\title{
A Long-term Numerical Study of the Potential Predictability of Seasonal Mean Fields of Water Resource Variables using MRI/JMA-AGCM
}

\author{
Tosiyuki NAKAEGAWA
}

Meteorological Research Institute, Japan Meteorological Agency, Tsukuba, Japan

Masato SUGI

Climate Prediction Division, Climate and Marine Department, Japan Meteorological Agency, Tokyo, Japan

and

Kei-ichi MATSUMARU

Meteorological Research Institute, Japan Meteorological Agency, Tsukuba, Japan

(Manuscript received 2 October 2002, in revised form 12 June 2003)

\begin{abstract}
Using the Meteorological Research Institute of Japan Meteorological Agency, atmospheric global model (MJ98), the potential predictability is investigated (maximum possible predictability when sea surface temperature (SST) is perfectly predicted) of the seasonal mean fields of four water resource variables, i.e. precipitation minus evaporation $(P-E)$, the terrestrial water storage, snow water equivalence, and runoff. 50-year (1949-1998) ensemble integrations are performed from six different initial conditions, forced with the same SST and sea ice cover.

The seasonal mean field variance ratios of the SST-forced variability, to the total variability, are computed to measure potential predictability of the four variables. The variance ratios of $P-E$ are generally high in the tropics, but low in the extratropics. The geographical pattern of potential predictability of the total terrestrial water storage is similar to that of $P-E$, since it is the net water flux into the ground surface. The variance ratios of snow water equivalence were as low in DJF as those of precipitation at high latitudes. However, the values in the coastal area of the Gulf of Alaska is high in MAM, although the other regions remained low. The geographical distribution of the variance ratio of runoff, has similar features to that of the total terrestrial water storage, but the values of the former are slightly lower than those of the latter.

High variance ratios are found in some areas of the extratropics. Singular value decomposition (SVD) analysis suggests that the ratios of $P-E$, and snow water equivalence, are due to the teleconnection forced by the tropical SST, while the higher variance ratio of the total terrestrial water storage is due to its persistence.
\end{abstract}

Corresponding author: Tosiyuki Nakaegawa, Climate Research Department, Meteorological Research Institute, Japan Meteorological Agency, 1-1 Nagamine, Tsukuba, Ibaraki 305-0052, Japan. E-mail: tnakaega@mri-jma.go.jp

(C) 2003, Meteorological Society of Japan

\section{Introduction}

In predicting the state of global water systems to 2025, it is apparent that water resources are more vulnerable to rising water demands than greenhouse warming (Vorosmarty 
et al. 2000). Thus, it is important to develop new water resources, and to manage available water resources efficiently. Developing new resources is a strategy to increase the absolute mass, while effective use management involves specific tactics. Long lead-time forecasting facilitates the correct management of water resources by employing integrated operations and regulations, which reduce the vulnerability. For example, forecasting the mean fields of natural water resources one season in advance, will greatly contribute to the improvement of the water resources management.

With the awareness of the value of forecasting, many studies have been dedicated to the seasonal forecast of the river runoff. The basic concepts in these studies are the same; sea surface temperatures (SSTs), and the southern oscillation index, are significant antecedent predictor of runoff. Statistical relationships were subsequently established, based on historical data for each river, such as the Amazon River (Uvo and Graham 1998), some rivers located in eastern Australia (Piechota et al. 1998; Sharma 2000) and those in the western part of the United States (Anderson et al. 2001). However, a dynamical forecast based on an atmospheric numerical model has not yet been applied to forecasting seasonal mean fields of water resource variables.

The chaotic nature, and instability of the atmospheric equations of motion to small perturbations, make seasonal forecast difficult and the deterministic forecast will not contain meaningful information. For a seasonal forecast, we expect the anomalous lower boundary conditions, such as SSTs, sea ice cover, soil moisture and snow cover, to be more important than the initial conditions, as suggested by Lorenz (1982). A stochastic estimate of the seasonal mean fields, the ensemble method, is obtained by averaging the realization values produced deterministically by multiple independent numerical integrations. Many studies examined the possibility of a seasonal mean fields forecast based on the dynamical methods (Palmer and Anderson 1994; Brankovic and Palmer 2000), and some international projects (concisely overviewed by Kusunoki et al. (2001)), were coordinated such as the Dynamical Seasonal Prediction Model Intercomparison Project (SMIP). The ensemble seasonal forecast sim- ulations are performed for seven months at most, and use the observed atmospheric data as initial conditions. These experiments revealed that the ensemble mean forecast improved in amplitude, and phase skill compared with individual forecasts (Kobayashi et al. 2000; Kusunoki et al. 2001). El Niño, and La Niña are the largest interannual variabilities in the lower boundary conditions, which can influence the predictability significantly. The spatial correlations were improved (Shukla 1998), and skill was enhanced during El Niño Southern Oscillation (ENSO) periods (Brankovic and Palmer 1997). ENSO has important impacts on runoff as well (Kiladis and Sinha 1991).

Another approach is to use ensemble climate simulations with the same SSTs, but start from different initial conditions. The ensemble climate simulations are performed for several decades consequently the initial conditions do not have any effect on the predictability. This can also clarify the possibility of seasonal mean fields forecast (Kumar and Hoerling 1995; Stern and Miyakoda 1995; Bengtsson et al. 1996; Sugi et al. 1997; Rowell 1998; Trenberth et al. 1998; Koster et al. 2000). The role of SST forcing in long-term atmospheric variability can be identified and the potential predictability under idealized "perfect model" conditions, can be estimated in this approach, because SST-forced variability and internally induced atmospheric variability are separated from the total variability, without the influence of any initial conditions that may contain predictable signals (Folland and Rowell 1995).

Previous studies analyzed only the possibility of dynamical seasonal forecasts of atmospheric variables, such as air temperature, precipitation, and the geopotential height. To develop the optimal management methodology, to reduce the vulnerability of the water resources, it will be significant to assess the potential predictability of the seasonal mean fields of water resource variables. The potential predictability is investigated based upon an ensemble climate simulation experiment of an atmospheric global climate model (AGCM), forced with observed SST. The numerical experiment and analysis are described in Section 2, and the reproducibility is verified in Section 3 . The results of the analysis, and their mechanisms are presented in Sections 4 and 5, fol- 
lowed by discussion and summary in Sections 6 and 7.

\section{Numerical experiment, analysis and data}

\subsection{Water resource variables}

$P-E$, total terrestrial water storage, snow water equivalence, and runoff are chosen as water resource variables. $P-E$ is the maximum potential available water mass referred to as potential water availability when we do not consider a river network function. Total terrestrial water storage is defined here as the summation of moisture in the soil layers in the model and snow water equivalence. This quantity is related to a plant available water mass, and can be considered as an index of the shallow groundwater level that, assuming the quasisteady condition, can be computed using Richard's equation (Beven and Kirkby 1979). Snowpack functions as a natural reservoir until a melting period. River runoff supplies humankind with a great amount of freshwater because of its accessibility. Note that the runoff in this model consists of surface runoff, and subsurface runoff, and does not include river network routing or groundwater movement.

\subsection{Numerical experiment}

a. Model

For the purpose of this study, the Meteorological Research Institute of Japan Meteorological Agency atmospheric global model (MJ98) was integrated at T42, spectral resolution. The horizontal resolution is a triangular truncation at total wave number 42 , and corresponds to about $300 \mathrm{~km}$. This model has 30 levels with a $0.5 \mathrm{hPa}$ top (Shibata et al. 1999). It includes the following parameterization for the physical processes. Arakawa-Schubert (PAS) scheme with prognostic closure similar to Randall and Pan (1993), is used for deep moist convection. A level-2 turbulence closure scheme based on Mellor and Yamada (1974) is used for vertical diffusion. The model calculates the solar radiation formulated with delta-two-stream approximation (Shibata and Uchiyama 1992), and the longwave radiation with a multi-parameter random model (Shibata and Aoki 1989). The land surface model is based on the Simple Biosphere ( $\mathrm{SiB}$ ) model (Sellers et al. 1986; Sato et al. 1989) (JMA-SiB). The climate research ver- sion of JMA-SiB has three soil layers (L3SiB), with different soil characteristics for each vegetation type, and predicts temperature, liquid water, and frozen water. The hydraulic properties such as the soil water retention curve and hydraulic conductivity, vary with frozen water contents in this model. The basic structure of the dynamical processes, and the physical processes are the same as those used in the Atmospheric Model Intercomparison Project (AMIP), with some parts improved for more realistic climate reproducibility. The systematic error of small precipitation, and higher surface air temperature over land was reduced by introducing the surface saturated infiltration (Nakaegawa and Sugi 2001); the systematic error of higher air temperature in winter polar regions was reduced by tuning the diffusion coefficient in the boundary layer.

\section{b. Experiment design}

The six-member ensembles were run for a 50year period from January 1, 1949 to November 30, 1998. The SSTs, and sea ice cover, were taken from Global Sea-Ice and Sea Surface Temperature Data Version 2.2 (GISST2.2) (Rayner et al. 1996). The initial data for the atmosphere and land were chosen on January 1 of a similar but independent long-term integration. The initial conditions for land can contain the long-term trend forced by the SST trend, because soil moisture has a long spin-up time especially at high latitudes. The trend of the total terrestrial water storage was checked and excluded the first ten years for the following analysis.

\subsection{Analysis}

The potential predictability as the maximum predictability that can be reached, is defined using a perfect model when the SST and sea ice cover are perfectly predicted. The standard statistical tool, "Analysis of variance," is used with data from an ensemble of climate simulations, to separate the total atmospheric variance $\left(\hat{\sigma}_{\text {TOT }}^{2}\right)$ of a time-averaged quantity into two components; variability forced by the lower boundary conditions of SST and sea ice $\left(\hat{\sigma}_{\mathrm{SST}}^{2}\right)$, and random internal variability $\left(\hat{\sigma}_{\mathrm{INT}}^{2}\right)$. The variance ratio $(\hat{R})$ is used as a measure of the potential predictability as

$$
\hat{R}=\frac{\hat{\sigma}_{\mathrm{SST}}^{2}}{\hat{\sigma}_{\mathrm{TOT}}^{2}}
$$


where

$$
\begin{aligned}
& \hat{\sigma}_{\mathrm{SST}}^{2}=\hat{\sigma}_{\mathrm{EM}}^{2}-\frac{1}{n} \hat{\sigma}_{\mathrm{INT}}^{2}, \\
& \hat{\sigma}_{\mathrm{TOT}}^{2}=\hat{\sigma}_{\mathrm{SST}}^{2}+\hat{\sigma}_{\mathrm{INT}}^{2}, \\
& \hat{\sigma}_{\mathrm{INT}}^{2}=\frac{1}{N(n-1)} \sum_{i=1}^{N} \sum_{j=1}^{n}\left(x_{i, j}-\bar{x}_{i}\right)^{2}, \\
& \hat{\sigma}_{\mathrm{EM}}^{2}=\frac{1}{N-1} \sum_{i=1}^{N}\left(\bar{x}_{i}-\overline{\bar{x}}\right)^{2} .
\end{aligned}
$$

Here, ^denotes the best estimator of a population quantity, and $\hat{\sigma}_{\mathrm{EM}}^{2}$ is the variance of the ensemble average interannual variability. $N$ is the number of integration years and $n$, the ensemble size. $x_{i, j}$ represents the realization value of $i$-th year and $j$-th member of the ensemble, $\bar{x}_{i}$ is the ensemble mean of the $i$-th year, and $\overline{\bar{x}}$ is the mean of all data. Note that these variances include effects of atmosphere-land interactions as well as that of atmosphere-sea interactions.

\subsection{Observed data}

A perfect model is assumed that reproduces the climate as a lower boundary problem as mentioned above, and, therefore, observed $P-E$ and snow water equivalence are compared with the simulated ones to evaluate reproducibility of the simulations in this study. $P-E$ is computed based on the atmospheric water balance method. It can be thus obtained from a residual of the water vapor convergence to the change in the atmospheric column storage of water vapor (Oki and Musiake 1995). The reanalysis data from 1979 to 1993 produced by the European Center for Medium range Weather Forecasts (ECMWF) (Gibson et al. 1999) were used to compute $P-E$. For the 1993/1994 winter, ECMWF operational analysis data were used. Snow water equivalence was computed from snow depth data retrieved from the Nimbus-7 Scanning Multichannel Microwave Radiometer (Chang et al. 1992), assuming the snow density was $300 \mathrm{~kg} / \mathrm{m}^{3}$. This data set covers October 1977, to August 1987.

The model climatological values for the same periods is computed as the observations, and compared the simulated and observed values.

\section{Reproducibility}

3.1 $P-E$

Figure 1 depicts the geographical distributions of the $P-E$ climatological mean, and the model's systematic errors. $P-E$ geographical patterns in both seasons were well reproduced. However, several quantitative deficiencies were found. The positive global model bias is broadly distributed in both seasons, while the strong negative one is concentrated. The magnitudes of the $P-E$ zonal mean differences between ECMWF and NMC, approximately $1 \mathrm{~mm} /$ day (Trenberth and Guillemot 1995), were almost the same as those between ERA15, and the simulated results (figure not shown), though the latitudinal distribution differed. Positive and negative error belts extended longitudinally over the Tropics, since the simulated Intertropical Convergence Zone (ITCZ) was located toward the south. Positive errors over the South Pacific Convergence Zone (SPCZ) were found, which were related to positive precipitation errors (not shown). Similar errors in other climate models were found (Gates et al. 1998; Brankovic and Palmer 2000). A pair of positive and negative errors occurred around steep topographical areas such as the Himalayan, eastern African, and Andes mountain ranges due to convection scheme difficulties in reproducing topographically induced precipitation. There were no significant systematic errors over land in Jun-July-August (JJA), except for the areas mentioned above, but there were positive errors in the Asian monsoon area and in Brazil in DJF.

\section{a. Snow water equivalence}

Figure 2 depicts the geographical distributions of the snow water equivalence climatological mean, and the model's systematic errors. Basic snow water equivalence geographical patterns were reproduced well in DecemberJanuary-Feburary (DJF), and March-April-May (MAM). However, positive errors are found in the coastal zone of the Gulf of Alaska, and Tibetan plateau, in both seasons and negative ones in Siberia. Positive errors are found in eastern Europe in DJF, and negative ones in a zone between $40^{\circ} \mathrm{N}$ and $60^{\circ} \mathrm{N}$ in MAM. The positive errors in the Tibetan plateau were due to topographical precipitation as mentioned 

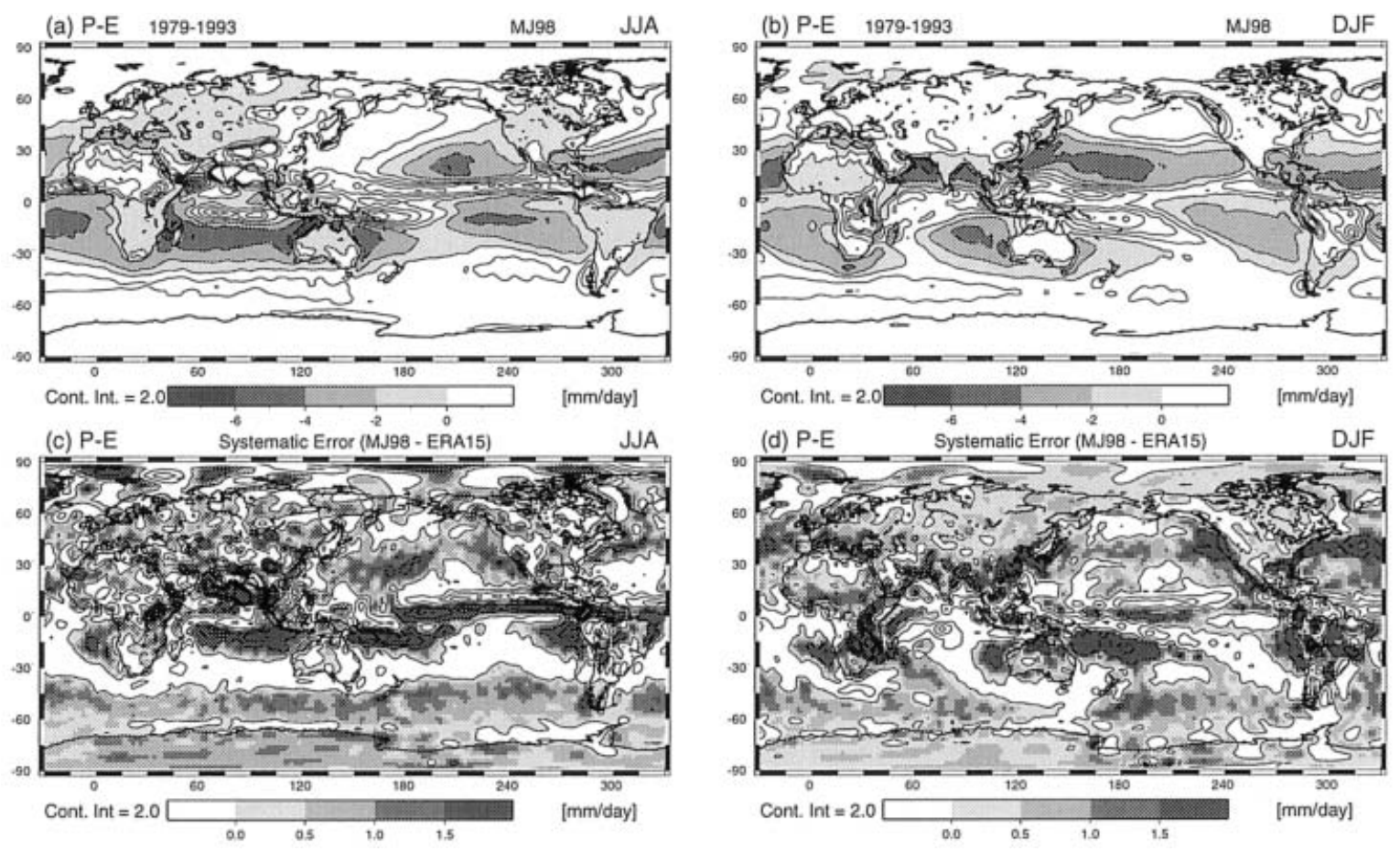

Fig. 1. $P-E$ climatological mean and its systematic model errors. The period of climatology is from 1979 to 1993. Climatology of (a) JJA and (b) DJF, and systematic errors of (c) JJA and (d) DJF. The contour lines drawn range only between -4 and 4 .

above. The negative errors in the midlatitude zone in MAM were due to simplified representation of snowmelting process in the JMA-SiB, which treated the snow layer and the surface soil layer as a single combined layer.

\subsection{Soil moisture and runoff}

The JMA-SiB model seasonal changes in soil moisture at some in-situ observation points were reproduced qualitatively, but not quantitatively, as well as the other models participating in the Global Soil Wetness Project (GSWP) (Entin et al. 1999). The JMA-SiB model is consistently close to the median of the GSWP models in the data series (Rodell and Famiglietti 1999). The GSWP experiment sought to produce soil wetness using a land surface model forced by the surface meteorological data (Dirmeyer et al. 1999).

The seasonal changes of continental scale river runoff produced by the JMA-SiB model in GSWP, were also reproduced well (Oki et al. 1999).

The model reproduced the climatological mean of the four variables sufficiently well, to assess their potential predictability. Its reproducibility was almost the same as other state-of-the-art climate models (e.g., Gates et al. 1998). Therefore, if we treat the model as 'perfect' for purpose of analyzing its predictability, the results should have bearing on predictability in the real world.

\section{Global potential predictability assessment}

\section{$4.1 P-E$}

Figure 3 depicts the geographical distribution of the variance ratio of $P-E$. The variance ratio was high in low latitudes, and low in mid and high latitudes. The variance ratio over land was lower than over oceans in the same latitude. Only the variance ratios in the Sahel and northern (tropical) part of South America remained high in both seasons. The variance ratios in India, Indochina and the Middle East were higher in JJA, but over Japan and the eastern part of China they were higher in DJF. The variance ratio was generally small in the 

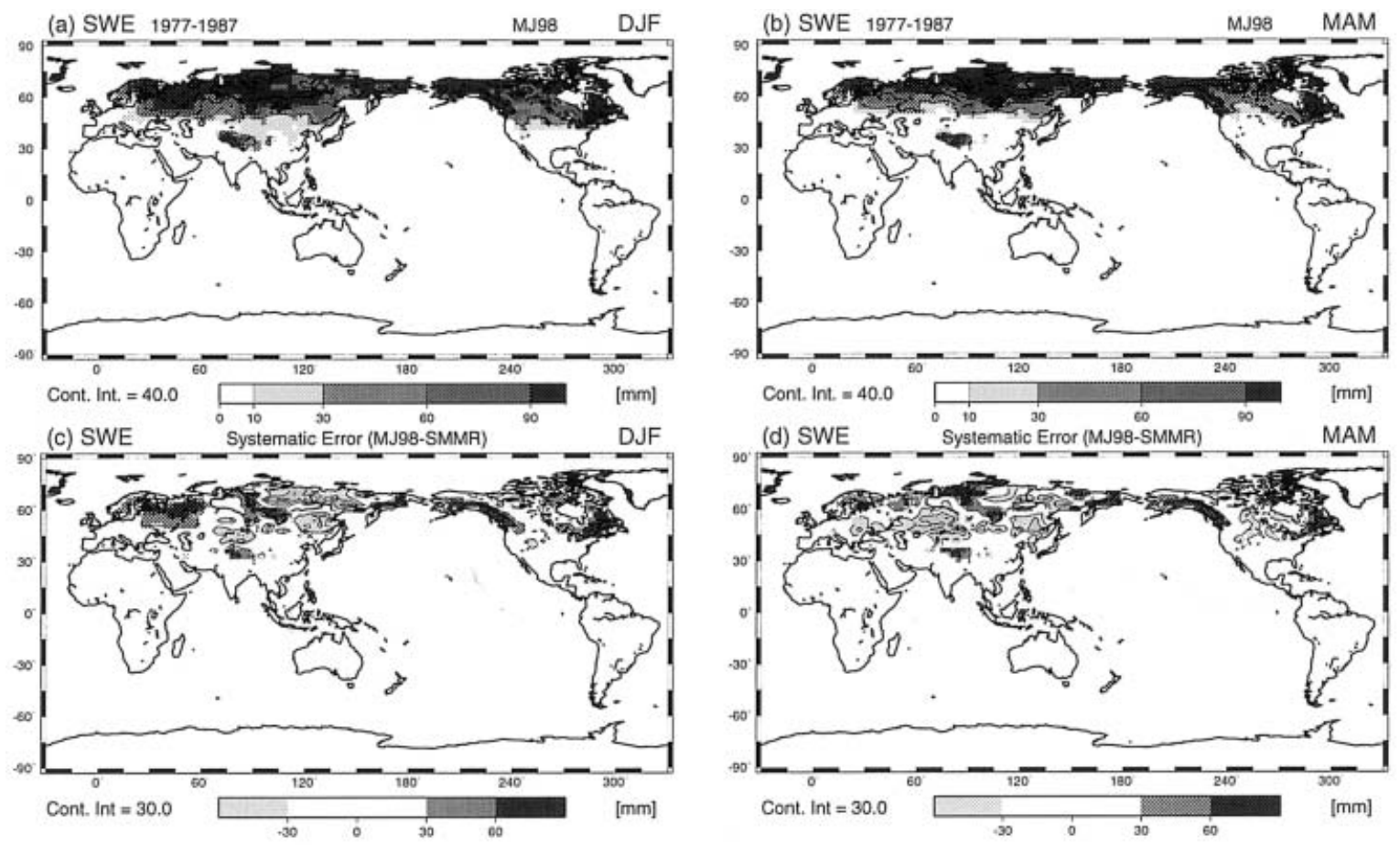

Fig. 2. Snow water equivalent climatological mean and its systematic model errors. The period of climatology is from 1977 to 1987. Climatological mean of (a) JJA and (b) DJF, and systematic errors of (c) JJA and (d) DJF. The contour lines drawn range only between -4 and 4 . The observed data were retrieved from SMMR (Chang et al. 1992), and snow density is assumed to be $300 \mathrm{~kg} / \mathrm{m}^{3}$.

extratropics, because the internal atmospheric variability is larger than the SST-forced one, but a higher variance ratio in JJA was found over the SPCZ. Midlatitude SST is somewhat forced by the atmosphere, and the high ratios might be related to the tropical SST by the SST-forced signals propagating to the extratropics.

The geographical distributions of the variance ratio of $P-E$ were more similar to those of precipitation, than those of evaporation (not shown these figures), and the areas with higher variance ratio of evaporation are larger than those of precipitation over both land and oceans. The SST-forced, and internal variances of precipitation are generally much larger than those of evaporation, and, therefore, the variance ratio of $P-E$ has more similar characteristics to that of precipitation than to that of evaporation.

\subsection{Total terrestrial water storage}

Figure 4 depicts the geographical distribution of the variance ratio of the total terrestrial water storage. Areas having a high variance ratio of more than 0.8 in JJA were confined to the southern part of the Amazon River basin, Nordeste (north-east Brazil), and Papua New Guinea. Other areas with high variance ratio are the Sahel, the tropical Asian Monsoon region, the central part of the United States, the East African Mountainous area and South Africa. Some basic patterns similar to JJA were also found in DJF, but the variance ratios in the eastern part of China and Borneo Island were significantly higher in DJF than in JJA. The hydrological season of JJA is not always the atmospheric season of JJA. For example, the water storage of the Amazon River basin, reaches the maximum value in MAM and the minimum value in SON in this experiment, which is consistent with those computed by Masuda et al. (2001), using a combined water balance method. Thus, we should keep it in our mind that we demonstrated two out of the four seasons and have difficulty in comparing the terrestrial water storages for different 

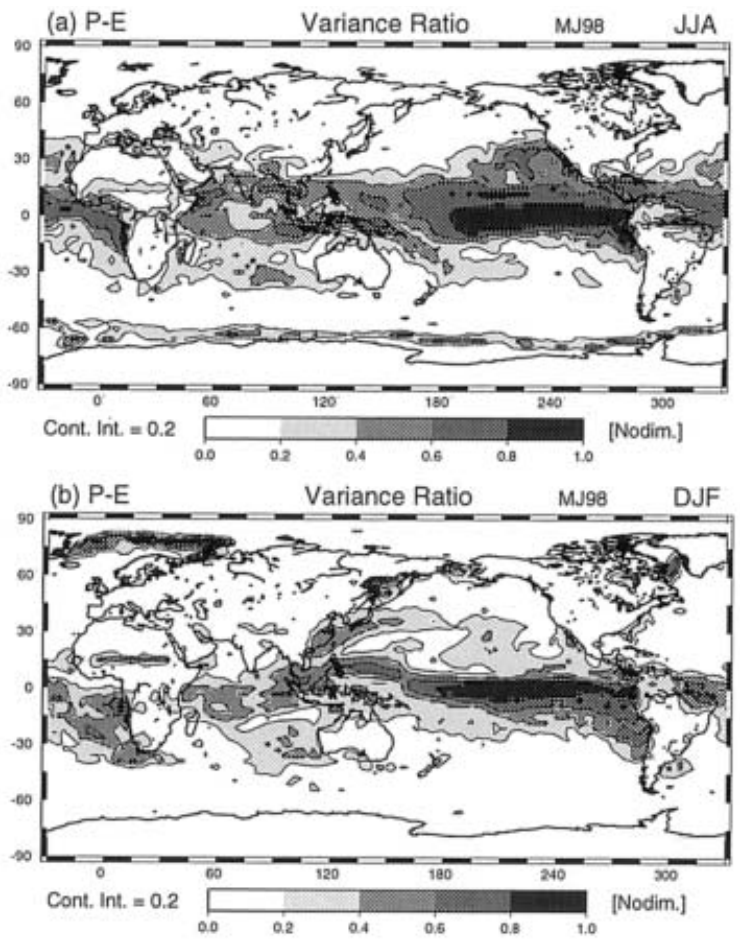

Fig. 3. The variance ratio of $P-E$, computed from the ensemble of six 19591998 runs. (a) JJA. (b) DJF.

regions under the same hydrological season. The total variability was higher in DJF in the Amazon River basin, and second lowest in JJA. However, the variance ratio did not change much in the two seasons. The variance ratio was higher in JJA in India, the Indochina peninsula, and the central part of the United States. Total terrestrial water storage is higher in JJA in the two Asian regions, but is lower in the central part of the United States. The terrestrial water storage interannual variation generally increases as the terrestrial water storage does so. However, such a relationship between the variance ratio, and the absolute storage is not found. The geographical distribution in Fig. 4 was similar to that of Fig. 3, but the ratios in the central part of the United States and South Africa are different. The difference might be related to soil's function as precipitation accumulator (Delworth and Manabe 1988).

\subsection{Snow water equivalence}

Figure 5 depicts the geographical distribution of the variance ratio of the snow water
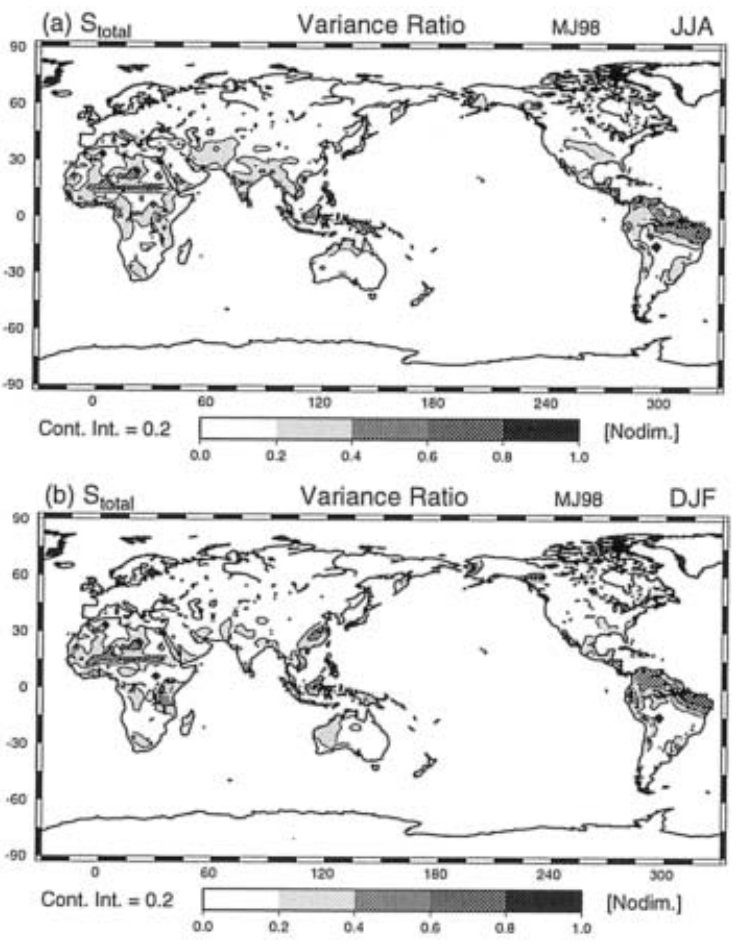

Fig. 4. Same as Fig. 3, but for the total terrestrial water storage. (a) JJA and (b) DJF.

equivalence. The ratios were generally low, (about 0.1 at highest in DJF and MAM). However the values in the Tibetan Plateau and in the coastal area of the Gulf of Alaska in MAM reach 0.2 . The higher variance ratio in the Tibetan Plateau can be explained from the higher $P-E$ variance ratio in DJF, as seen in Fig. 3 . The climatological snowmelting period in the coastal area was from April to May in this simulation. Snowmelting rate depends on many variables such as net radiation, snow depth, wind speed, air temperature and humidity. The snow melts only when the snow temperature exceeds $0^{\circ} \mathrm{C}$. The $P-E$ variance ratio was low in both DJF and MAM, but that of surface air temperature (not shown) was quite high. Thus, the higher variance ratio of snow water equivalence is believed to be related to the snowmelting processes.

\subsection{Runoff}

Figure 6 depicts the geographical distribution of the variance ratio of runoff. The basic pattern in this figure was similar to that of Fig. 

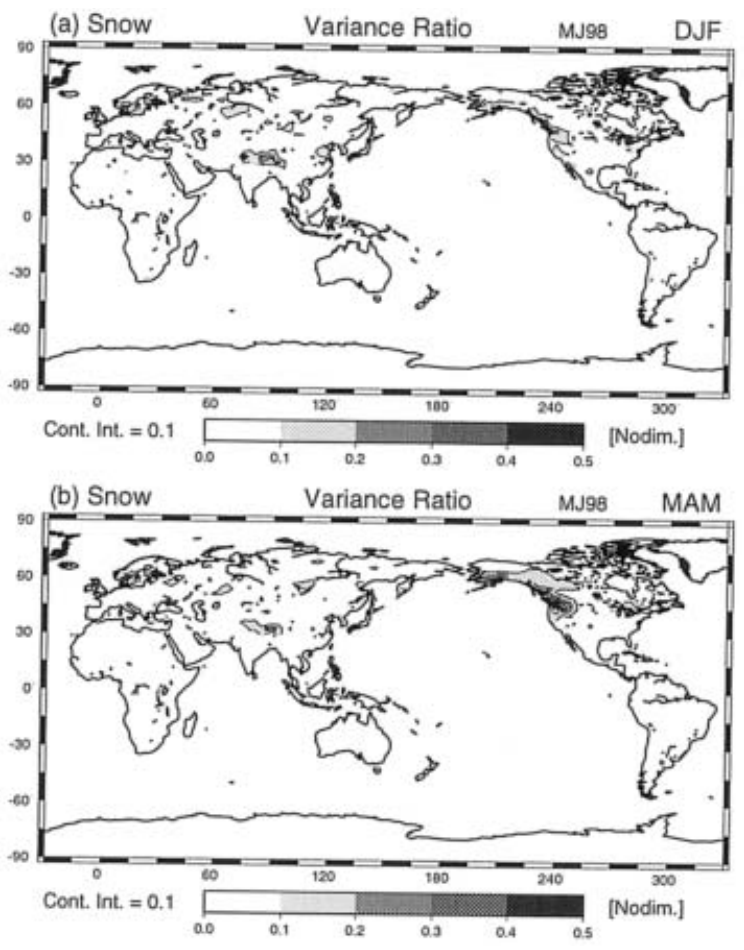

Fig. 5. Same as Fig. 3 but for snow water equivalent. (a) DJF. (b) MAM.

4 , but the variance ratios were generally lower than those in Fig. 4. Higher values in JJA exceeding 0.2 were confined in the southern part of the Amazon River basin, Nordeste, India, and the Indochina peninsula. Higher values in DJF were located in the southern part of the Amazon River basin, Nordeste and the eastern part of China.

\section{Physical mechanism}

The geographical distribution of the variance ratio is shown for the four variables relevant to water resources. High variance ratios were generally distributed in low latitudes, and low ones were distributed in mid- and high latitudes. However, some distinct patterns of variance ratios were found even in mid- and high latitudes. In this section, their possible mechanisms are considered.

\section{$5.1 P-E$}

Ogallo et al. (1988), and Shinoda and Kawamura (1996) revealed a strong relationship be-
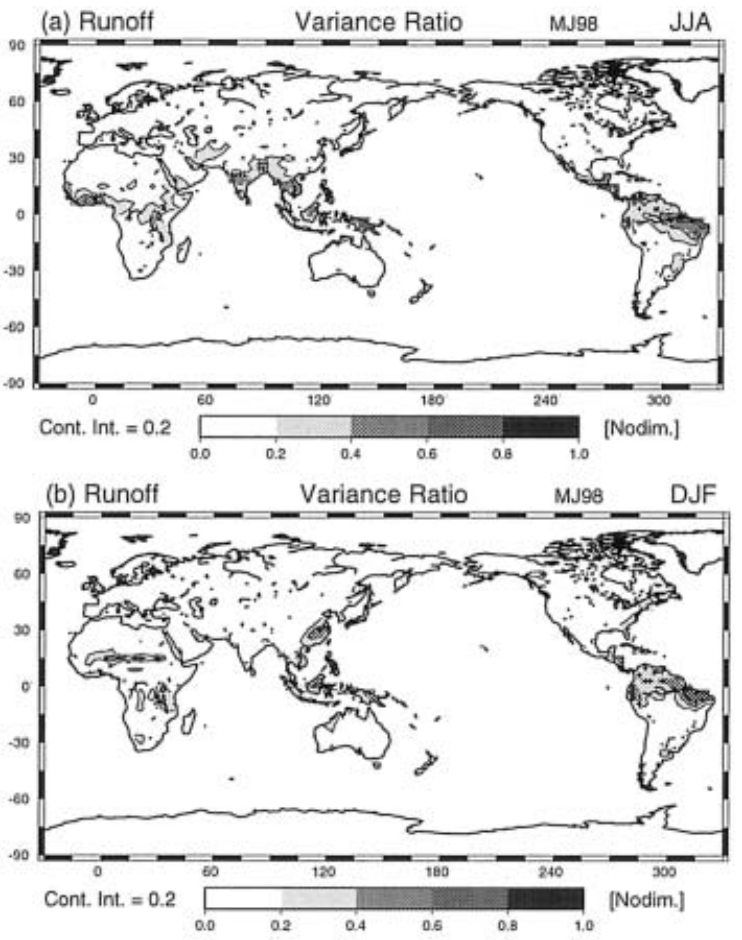

Fig. 6. Same as Fig. 3 but for runoff. (a) JJA and (b) DJF.

tween tropical SST and precipitation in the Sahel from the data analysis. Nobre and Shukla (1996) revealed an SST/Precipitation relationship in Nordeste as well. It is well-known that AGCMs can reproduce the interannual variation of observed precipitation in the Sahel (e.g., Sperber and Palmer 1996; Brankovic and Palmer 2000) and in Nordeste (e.g., Ward and Folland 1991; Gates et al. 1998). Koster and Suarez (1995) and Koster et al. (2000) clarified that land and ocean processes have essentially different domains of influence. The amplification of precipitation variance by land-atmosphere feedback is most important in the extratropics and not in the tropics. Thus, the tropical atmosphere is substantially governed by the tropical SST, and the SST-forced variability dominates the total variability. However, the variance ratio of precipitation is not high in the Sahel in DJF because of the dry season. The tropical SST does not control precipitation, but net radiation at the Earth's surface. Therefore, the higher variance ratio of 
evaporation is responsible for the higher variance ratio of $P-E$ through the higher variance ratio of the net radiation (not shown).

Dynamical atmospheric processes, such as teleconnection, must be presented for the high values to exist in mid- and high latitudes. Lau and Nath (2000) computed the distributions of the warm minus cold composite of anomalous streamline patterns simulated in AGCM experiments, and showed dry conditions are typically coincident with low-level anticyclonic anomalies over the northwestern subtropical Pacific, and vice versa. This is essentially a Rossby-type response (Matsuno 1966; Gill 1980) to reduced condensational heating over the western equatorial Pacific during warm ENSO events (Lau and Nath 2000). The southwestern anomalous wind accompanied with this anomalous circulation in DJF brings warm and humid air from the northwestern subtropical Pacific, and Japan tends to receive more precipitation especially in its southern part, as well as the eastern part of China. As a result, the variance ratio of $P-E$ is higher than that of the other areas within the same latitudinal zone.

The Singular value decomposition method was used to verify the effect of the tropical SST on the above mechanism. The method identifies pairs of coupled spatial patterns, and their temporal variation with each pair explaining a fraction of the covariance between the two fields (Bjornsson and Venegas 1997). Figure 7 depicts the heterogeneous loading factor maps of the first SVD mode of the simulated Northern Hemisphere $\left(0^{\circ}-90^{\circ} \mathrm{N}\right) 500 \mathrm{hPa}$ height field, and the SST used in the simulation with a timeseries score for DJF. The first mode of the SST is related to ENSO, as indicated by its pattern. There is a dipole pattern of $500 \mathrm{hPa}$ height field over the ocean to the south of Japan. This coincides with the result of Lau and Nath (2000), and the Matsuno-Gill response formulates the anomalous circulation around Japan. Therefore, the variance ratios are higher in Japan, and in the coastal area of China in DJF.

\subsection{Total terrestrial water storage}

The higher values of the variance ratio in the Sahel, East African Mountainous area and Nordeste are due to precipitation and $P-E$ directly

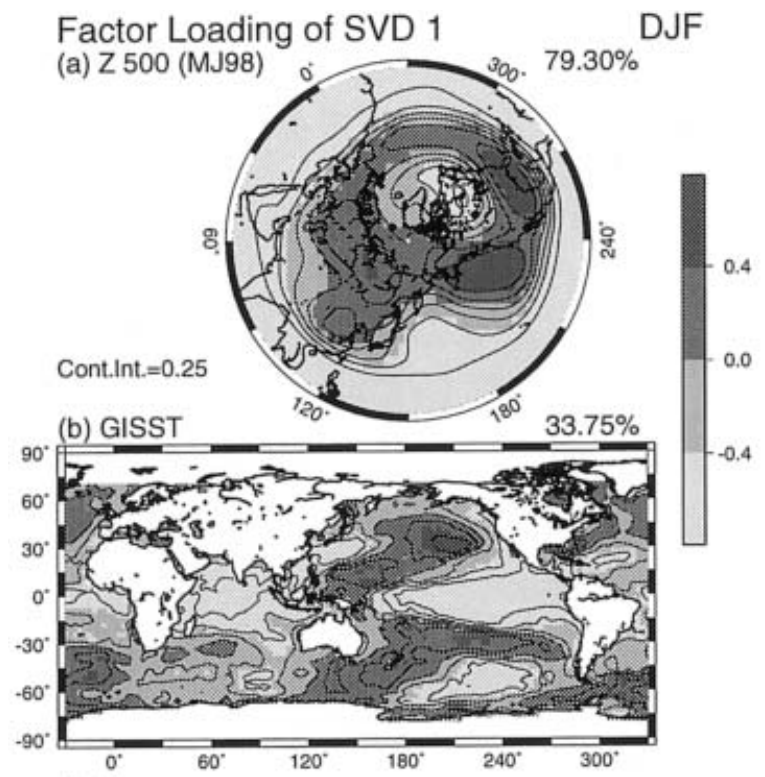

(c) Score

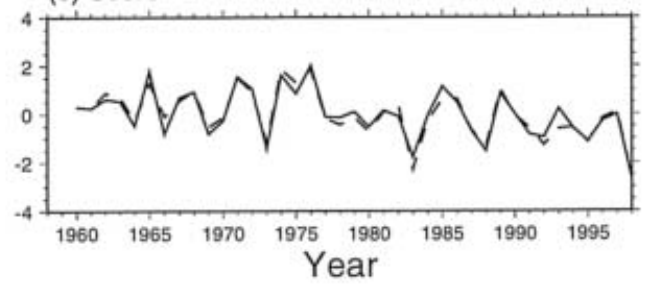

Fig. 7. Heterogeneous correlation maps of the first singular value decomposition (SVD) mode of (a) the simulated Northern Hemisphere $\left(0^{\circ}-90^{\circ} \mathrm{N}\right)$ $500 \mathrm{hPa}$ height field and (b) SST used in the simulation (c) with a time-series of score for DJF. The solid line represents the score of SST, and dashed line, $500 \mathrm{hPa}$ height.

forced by tropical SST, as mentioned above. Soil moisture interannual variations are small in the Sahel in DJF, because DJF in the Sahel is the dry season (e.g., Yamaguchi and Shinoda 2002). The higher variance ratio suggests that, though soil moisture interannual variations are small, they are controlled by tropical SST through evaporation, as mentioned above. The variance ratio of terrestrial water storage in South Africa exceeds 0.2 for all seasons, while the values of variance ratio of $P-E$ exceeds 0.2 only in DJF. The high variance ratio of $P-E$ in $\mathrm{DJF}$ is directly responsible for the variance ratio of terrestrial water storage, but not in 
the other seasons because the variance ratio of $P-E$ is less than 0.1. Delworth and Manabe (1988) showed that the time series of soil moisture can be generated from a first-order Markovian process model. This characteristic was verified against the observed data (Vinnikov and Robock 1996). If the decay time scale of soil moisture is long enough, then the SST-forced signals of the total terrestrial water storage in DJF possibly propagate to consecutive seasons. The propagation of the signal of the terrestrial water storage in DJF can be said to be that of $P-E$ in DJF as a first-order approximation. The variance ratios of the terrestrial water storage in the central part of the United States exceeds 0.2 in all seasons, although those of $P-E$ never exceed 0.15 . The same process can exist in the central part of the United States too.

Here we use a simple model analogous to the Markovian process model and estimate the variance ratio to verify the importance of this propagation process on the relatively higher variance ratio in the two regions. First, the Markovian process can be written as,

$$
\frac{\partial S}{\partial t}=-\alpha S+\varepsilon,
$$

where $S$ is the total terrestrial water storage, $\alpha$ the first-order coefficient of the autocorrelation model (or inversely decay time scale), $\varepsilon$ forcing term equal to precipitation. The discrete form can be written as,

$$
S_{n+1} \simeq(1-\alpha \Delta t) S_{n}+\Delta t \varepsilon_{n+1},
$$

where the subscript represents the discretized time. By rewriting Eq. (7) using the anomalous values and squaring both sides, a first-order approximation of the propagation of variance can be obtained as,

$$
\begin{aligned}
\hat{\sigma}_{\mathrm{SST}}^{2}\left(S_{n+1}^{\prime}\right) \simeq & (1-\alpha \Delta t)^{2} \hat{\sigma}_{\mathrm{SST}}^{2}\left(S_{n}^{\prime}\right) \\
& +\Delta t^{2} \hat{\sigma}_{\mathrm{SST}}^{2}\left((P-E)_{n+1}^{\prime}\right),
\end{aligned}
$$

where prime represents the anomaly from the climate values and, for simplicity, we ignore the correlation terms and assume $\varepsilon_{n}^{2}=\hat{\sigma}_{\mathrm{SST}}^{2}\left(P^{\prime}\right) \sim$ $\sigma_{\mathrm{SST}}^{2}\left((P-E)^{\prime}\right)$ because $\sigma_{\mathrm{SST}}^{2}\left(P^{\prime}\right)$ is one order of magnitude larger than $\sigma_{\mathrm{SST}}^{2}\left(E^{\prime}\right)$. This equation means that the variance of the terrestrial water storage can show some structure in later seasons, even when the variance of precipitation

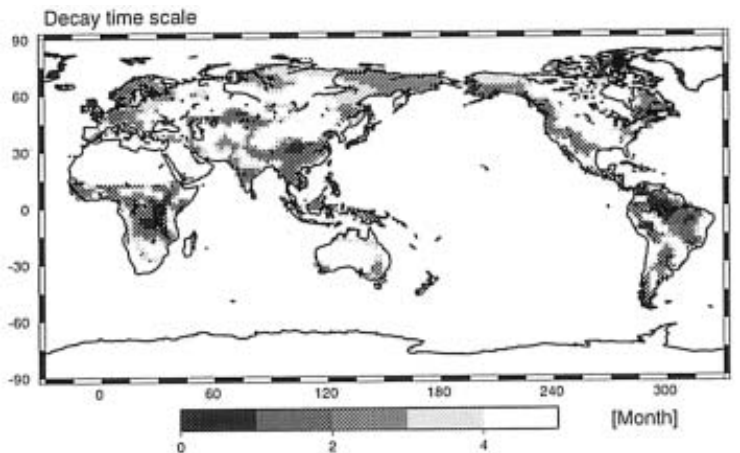

Fig. 8. Geographical distribution of the decay time scale of the total terrestrial water storage.

has lost its SST-forced structure because of the terrestrial water storage persistence. Figure 8 depicts the geographical distribution of the anomalous total terrestrial water storage decay time scale where the value is equal to the inverse of the first-order coefficient of the autocorrelation. Basic global pattern of the decay time is consistent with that obtained by Delworth and Manabe (1988), Liu and Avissar (1999), and Koster and Suarez (2001). The time scales have pronounced latitudinal dependence, due to the net radiation at the Earth's surface (Delworth and Manabe 1988) and have some regionality in the same latitude due to the actual evaporation (Liu and Avissar 1999). However we use the anomaly for its computation following Koster and Suarez (2001) and there are large decay time scales in arid regions. South Africa has a longer soil moisture decay time scale, of more than six months.

Let us consider the area of South Africa having the values of the variance ratio exceeding 0.2 . The variance ratio approximately is estimated as,

$$
\begin{aligned}
\hat{R}_{\mathrm{SST}}\left(S_{n+1}^{\prime}\right)= & \hat{\sigma}_{\mathrm{SST}}^{2}\left(S_{n+1}^{\prime}\right) /\left(\hat{\sigma}_{\mathrm{SST}}^{2}\left(S_{n+1}^{\prime}\right)\right. \\
& \left.+\hat{\sigma}_{\text {INT }}^{2}\left((P-E)_{n+1}^{\prime}\right)\right),
\end{aligned}
$$

where a time evolution of $\hat{\sigma}_{\mathrm{SST}}^{2}\left(S^{\prime}\right)$ is computed using Eq. (8). The climatological mean values of the variances are used for this computation. Table 1 shows the simulated variance ratios with the climatological mean of the variability, the model results $\left(\hat{\sigma}_{\mathrm{INT}}^{2}(P-E)\right.$ and $\left.\hat{\sigma}_{\mathrm{SST}}^{2}(P-E)\right)$, and the simple model results $\left(\hat{\sigma}_{\mathrm{SST}}^{2}(S)\right)$. Two de- 
Table. 1. The variance ratio of the total terrestrial water storage derived from the simulation and that estimated from the first-order Markovian process model. $\sigma_{\text {INT }}^{2}(P-E)$ and $\sigma_{\mathrm{SST}}^{2}(P-E)$ are the internal and SST-forced variability of $P-E, \hat{R}(P-E)$ and $\hat{R}(S)$ are the variance ratio of $P-E$, the total terrestrial water storage in the simulation, and $\sigma_{\mathrm{SST}, t_{d}}^{2}(S)$ and $\hat{R}_{t_{d}}(S)$ are the SST-forced variability and the variance ratio of the total terrestrial water storage for the decay time scale of $t_{d}$ estimated from the Markovian process model of the first-order.

(a) South Africa

\begin{tabular}{l|cccc|cccc}
\hline \hline & \multicolumn{4}{|c|}{ Experiment Results } & \multicolumn{4}{c}{ Markovian Model } \\
Season & $\sigma_{\mathrm{INT}}^{2}(P-E)$ & $\sigma_{\mathrm{SST}}^{2}(P-E)$ & $\hat{R}(P-E)$ & $\hat{R}(S)$ & $\sigma_{\mathrm{SST}, 7}^{2}(S)$ & $\hat{R}_{7}(S)$ & $\sigma_{\mathrm{SST}, 8}^{2}(S)$ & $\hat{R}_{8}(S)$ \\
\hline DJF & 0.800 & 0.190 & 0.192 & 0.297 & 0.191 & 0.193 & 0.191 & 0.193 \\
MAM & 0.427 & 0.041 & 0.088 & 0.287 & 0.103 & 0.194 & 0.115 & 0.212 \\
JJA & 0.074 & 0.006 & 0.075 & 0.296 & 0.040 & 0.349 & 0.051 & 0.408 \\
SON & 0.091 & 0.002 & 0.022 & 0.308 & 0.027 & 0.288 & 0.032 & 0.194 \\
\hline \hline
\end{tabular}

(b) Central US.

\begin{tabular}{l|llll|llll}
\hline \hline DJF & 0.476 & 0.096 & 0.146 & 0.240 & 0.101 & 0.175 & 0.102 & 0.176 \\
MAM & 0.482 & 0.083 & 0.147 & 0.254 & 0.116 & 0.194 & 0.123 & 0.203 \\
JJA & 0.337 & 0.037 & 0.099 & 0.278 & 0.075 & 0.182 & 0.085 & 0.201 \\
SON & 0.355 & 0.016 & 0.043 & 0.240 & 0.040 & 0.101 & 0.049 & 0.120 \\
\hline \hline
\end{tabular}

cay time scales are used, $1 / \alpha=7,8$ month for these computations.

The variance ratio becomes higher when the propagation of $\sigma_{\mathrm{SST}}^{2}(S)$ is introduced, and remains high in all four seasons, though the seasonal change is not reproduced very well. Therefore, the propagation of the SST-forced variability in DJF, as a main factor, keeps the variance ratio there high year round. The estimated ratio using Eq. (9) is tabulated in Table 1. It is smaller than the variance ratio in the simulation, but higher when the simple model is incorporated. The variance ratio remains relatively high, and relatively low SST-forced variability is accumulated because of the long soil moisture decay time scale. Many previous works showed the importance of the land processes on precipitation and ground air temperature over the United States (e.g., Walsh et al. 1985; Koster and Suarez 1995; Koster et al. 2000; S.-Y. Hong and Kalnay 2002). The essence of the land processes among them is a relatively longer persistence of the soil moisture, which is the same as the higher variance ratio.

\subsection{Snow water equivalence}

The Snowmelting rate can be estimated from degree-days, which is the accumulated daily mean ground air temperature, because the air temperature completely reflects radiation, wind, and humidity. Thus, if the potential predictability of air temperature is high, then that of snow water equivalence should also be high. Figure 9 depicts the heterogeneous loading factor maps of the first SVD mode of the simulated Northern Hemisphere $\left(0^{\circ}-90^{\circ} \mathrm{N}\right)$ $500 \mathrm{hPa}$ air temperature field and the SST used in the simulation, with a time series score for MAM. Negative anomalous air temperature appears distinctly over the northern part of eastern Pacific during El Niño periods, while a strong positive one appears over the northern part of North America. One possible mechanism of the higher variance ratio along the coastal area of the Gulf of Alaska is linkage to the Pacific/North American pattern (PNA) (Barnston and Livezey 1987). Held et al. (1989) identify the mechanism of cyclonical anomalous circulation in response to El Niño over the eastern part of the North Pacific in winter seen in Fig. 7, using a linearized baroclinic stationary wave model. Anomalous tropical heating over the eastern Pacific produces transient anomalies in the upper tropospheric vorticity fluxes and the extratropical wave train subsequently responds to the transient anomalies. 


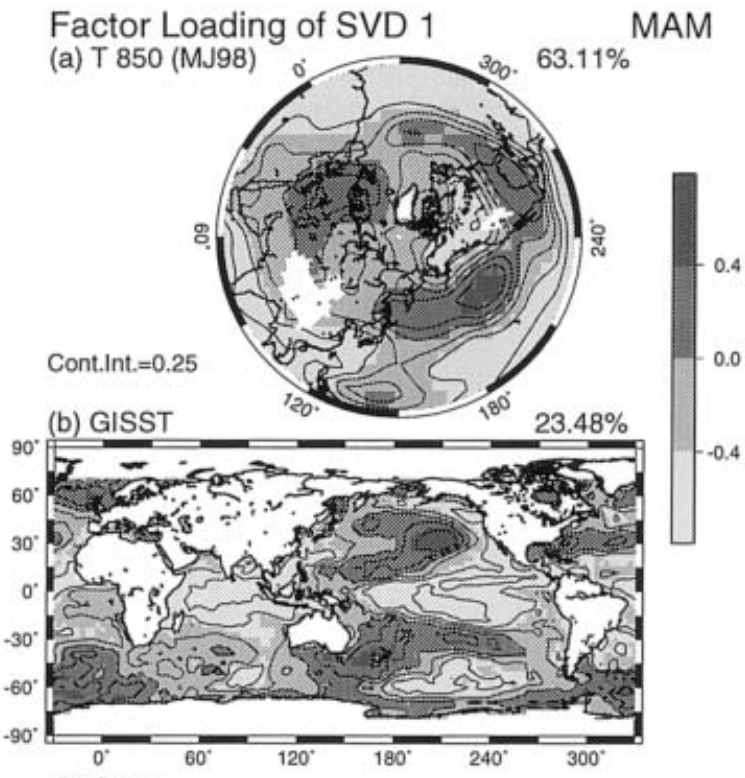

(c) Score

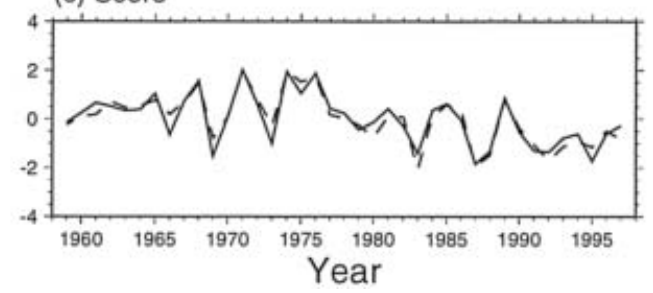

Fig. 9. Same as Fig. 7 but for $850 \mathrm{hPa}$ air temperature and in MAM.

This mechanism should be present in MAM too and maintain the patterns shown in Fig. 9, since the climatological PNA pattern exists in DJF and MAM (Barnston and Livezey 1987). Thus, the high variance ratio of air temperature is due to the existence of the teleconnection forced by tropical SST over the coastal area. As mentioned earlier, the snowmelting rate can be estimated from air temperature and, as a result, snow water equivalence remaining in the snowmelting period, can be as well. Therefore the high variance ratio of air temperature, is responsible for the high variance ratio of snow water equivalence in MAM when these relationships are translated to the variance ratio.

\subsection{Runoff}

As mentioned earlier, the runoff in this model consists of the surface and subsurface runoff. The geographical distribution of the variance
Table. 2. Upper and lower limits of $90 \%$ confidence interval for the estimated values of variance ratio.

\begin{tabular}{lcc}
\hline \hline Estimated Value & Lower limit & Upper limit \\
\hline 0.0 & 0.00 & 0.08 \\
0.1 & 0.02 & 0.21 \\
0.2 & 0.11 & 0.32 \\
0.3 & 0.19 & 0.43 \\
0.4 & 0.29 & 0.53 \\
0.5 & 0.39 & 0.62 \\
0.6 & 0.49 & 0.71 \\
0.7 & 0.61 & 0.79 \\
0.8 & 0.73 & 0.86 \\
0.9 & 0.86 & 0.93 \\
1.0 & 1.00 & 1.00 \\
\hline \hline
\end{tabular}

ratio of runoff, and that of the total terrestrial water storage, are similar because the subsurface runoff is a function of soil moisture in the bottom layer. The former is slightly lower than the latter, because of surface runoff. Surface runoff occurs when it rains heavily and, the rainfall intensity for each event is important for estimating the surface runoff rather than the rainfall seasonal mean value. The reproducibility of the frequency of the rainfall intensities has not been studied yet, because it is much more difficult than that of the seasonal mean prediction as shown in Fig. 3, and as demonstrated by other studies (e.g., Brankovic and Palmer 2000; Kusunoki et al. 2001). Therefore, the variance ratio of the runoff is lower than that of the total terrestrial water storage due to low variance ratio of the surface runoff.

\section{Discussion}

\subsection{Ensemble size}

The lower and upper limits of confidence intervals for the estimated variance ratio can be computed from the $F$-distribution function, with $N-1$ and $N(n-1)$ degrees of freedom. In this study, the two degrees are $N-1=39$ and $N(n-1)=200$. Table 2 shows both limits of $90 \%$ confidence intervals. The higher the variance ratio, the shorter the confidence interval. The variance ratio is thus more reliable in the tropics than in the extratropics. The confidence intervals are shorter than those of Sugi et al.'s (1997) experiment, that had an ensemble size of three, and 40-year integration. The maxi- 
mum possible error in variance ratio estimation at the $90 \%$ confidence level, for instance, improves from 0.2 to 0.1 when the estimated value of the variance ratio is less than 0.3. Brankovic and Palmer (1997) estimated the minimum useful ensemble size for 2-m temperature and precipitation, to be approximately 20-member ensembles for extratropical predictions. Their result suggested statistically that a higher number of the ensembles is needed to obtain reliable values.

\subsection{Model dependency}

The geographical distribution of the variance ratio of precipitation in this study (not shown here) is quite similar to that of Sugi et al. (1997) in both JJA and DJF, except in JJA for the tropical Asian monsoon region and the Sahel, and in DJF near Japan. The major differences between the JMA/Global Spectral Model88 (GSM88) used by Sugi et al. (1997), and MJ98, is the deep convection scheme. Kuo (1974) scheme is used in GSM88, while PAS scheme is used in MJ98. As a result of stronger teleconnection, the variance ratio in this study can be higher in the midlatitudes than that of Sugi et al. (1997), since PAS is more affected by SST than the Kuo scheme. The geographical distributions possibly have the same basic characteristics irrespective of different models, and different ensemble sizes as Folland and Rowell (1995) showed. However, as noted above, there are some discrepancies in certain areas. Moreover, soil moisture persistence is higher in the MJ98 model used here than in GSM88 (Nakaegawa and Sugi 2001). Therefore the variance ratio estimated from the simulation by GSM88, may be lower than that shown in Fig. 4. There are varieties of land surface schemes, such as BATS (Dickinson et al. 1986) and Mosaic (Koster and Suarez 1989), and these may be possible sources of model dependency, especially for the water resource variables that are closely related to the land surface processes.

Chen and Kumar (2002) computed the crosscorrelation between the ENSO index, and the anomaly of snow water equivalence derived from offline simulation using a large-area-basin model forced by the ERA-15. Their cross correlation reveals that the anomaly of snow cover is significantly related to ENSO and exhibits sev- eral months delay compared with ENSO. This reinforces our result of a higher variance ratio of snow water equivalence through the teleconnection forced by the tropical SST.

\section{Summary}

Potential predictability of the seasonal mean fields of the four variables relevant to water resources were estimated based on a six-member 50-year ensemble simulation using a T42L30 version of MJ98. The integrations were started from different initial conditions, and integrated with the historical global SST and sea ice cover data of GISST2.2.

The potential predictability of $P-E$ was higher in the lower part of the Amazon River basin, the northern part of South America, Papua New Guinea, and the Sahel in both JJA and DJF. It was higher in the tropical Asian monsoon and Middle East in JJA, and Japan and the eastern part of China in DJF. The variance ratios, the index of potential predictability used here, were confined to the latitudes below $30^{\circ}$.

The geographical pattern of the total terrestrial water storage potential predictability is similar to that of $P-E$ since $P-E$ is the net water flux into the ground surface. Variance ratios of the total terrestrial water storage exceeding those of $P-E$ were found in South Africa and the central part of the United States where there is longer soil moisture persistence. Soil moisture integrates precipitation (or $P-E$ ) (Delworth and Manabe 1988), and therefore the predictable signals propagated themselves to a consecutive season, which could be simulated well by the first-order Markovian model.

The variance ratios of snow water equivalence were as low as those of precipitation at high latitudes in DJF. However, the values in the coastal area of the Gulf of Alaska exceeded 0.2 in MAM, although the other regions remained low. This is not due to the land processes but due to air temperature. ENSO signals in the tropical SST excite PNA pattern through the teleconnection mechanism, and the variance ratio of air temperature becomes high. Therefore, the variance ratio of snow water equivalence is high through the snowmelt process, which is a function of air temperature.

The geographical distribution of the variance ratio of runoff has features similar to those 
of the total terrestrial water storage, but the values of the former are slightly lower. Values exceeding 0.2 are confined to limited areas because the surface runoff, one of the components of the runoff, is less predictable.

Based on these results, technological and economic seasonal water resource management studies are needed for practical utility. We have to provide more reliable and robust results to complete applied studies. We finally reiterated that we assumed "perfect forecast of SST" and "perfect representation of the atmosphere and land processes." In practice, predicting water resource variables may be more difficult than implied here because of imperfect SST forecasts, and model's systematic errors.

\section{Acknowledgments}

The GISST was provided by Hadley center under the Climate of the 20th century international project, and the ERA-15 was provided under a contract between JMA and ECMWF. The Nimbus-7 SMMR Derived Monthly Global Snow Depth data was provided by NSIDC, University of Colorado. Dr. A. Kitoh, K. Takano and other colleagues at MRI provide us useful comments. This study was conducted as a part of the special research project "Water Resource and Its Variability in Asia in the 21st century" granted by the Ministry of Education, Culture, Sports, Science, and Technology of Japan, and a part of the routine research project "state-ofthe-art seasonal forecast technology" at MRI.

\section{References}

Anderson, M., M. Kavvas and M. Mierzwa, 2001: Probabilistic/ensemble forecasting: a case study using hydrologic response distributions associated with El Niño/Southern Oscillation (ENSO). J. Hydrol., 249, 134-147.

Barnston, A.G. and R.E. Livezey, 1987: Classification, Seasonality and persistence of lowfrequency atmospheric circulation patterns. Mon. Wea. Rev., 115, 1083-1126.

Bengtsson, L., K. Arpe, E. Roeckner and U. Shulzweida, 1996: Climate predicability experimets with general circulation model. Clim. Dyn., 12, 261-278.

Beven, K. and M.J. Kirkby, 1979: A physically based variable contributing area model of basin hydrology. Hydrol. Sci. J., 24, 43-69.

Bjornsson, H. and S. Venegas, 1997: A Manual for EOF and SVD Analyses of Climate Data.
C2gcr report 97-1, McGill University, Motreal, Canada.

Brankovic, C. and T.N. Palmer, 1997: Atmospheric seasonal predictability and estimates of ensemble size. Mon. Wea. Rev., 125, 859-874. and - 2000: Seasonal skill and predictability of ECMWF PROVOST ensembles. Quart. J. Roy. Meteor. Soc., 126, 2035-2067.

Chang, A.T.C., J.L. Foster, D.K. Hall, H.W. Powell and Y. Chien, 1992: Nimbus-7 SMMR Derived Global Snow Depth Data Set. The Pilot Land Data System. Technical report, NASA/Goddard Space Flight Center, Greenbelt, MD.

Chen, J. and P. Kumar, 2002: Role of terrestrial hydrologic memory in modulating ENSO impacts in North America. J. Climate, 67, in print.

Delworth, T.L. and S. Manabe, 1988: The Influence of Potential Evaporation on the Variables of Simulated Soil Wetness and Climate. J. Climate, 2, 523-547.

Dickinson, R.E., A. Henderson-Sellers, P. Kennedy and M.F. Wilson, 1986: Biosphere/Atmosphere Transfer Scheme (BATS) for the NCAR Community Climate Model. Technical report, NCAR.

Dirmeyer, P.A., A.J. Dolman and N. Sato, 1999: The Pilot Phase of the Global Soil Wetness Project. Bull. Amer. Meteor. Soc., 80, 851-878.

Entin, J.K., A. Robock, K.Y. Vinnikov, V. Zabelin, S. Liu, A. Namkhai and T. Adyasuren, 1999: Evaluation of Global Soil Wetness Project Soil Moisture Simulations. J. Meteor. Soc. Japan, 77, 183-191.

Folland, C. and D. Rowell eds., 1995: Workshop on simulations of the climate of the twentieth century using GISST. No. 56 in CRTN, Bracknell, UK, Hadley Center.

Gates, W.L., I.S. Boyle, C.C. Covey, C.G. Dease, C.M. Doutriaux, R.S. Drach, M. Fiorino, P.J.G.J.J. Hnilo, S.M. Marlais, T.J. Phillips, G.L. Potter, B.D. Santer, K.R. Sperber, K.E. Taylor and D.N. Williams, 1998: The overview of the results of the Atmospheric Model Interecomparison Project (AMIP). PCMDI Report 45, Lawrence Livermore Laboratory, CA.

Gibson, J.R., P. Kallberg, S. Uppala, A. Hernandez, A. Nomura and E. Serrano, 1999: ERA-15 description (Version 2), Part 1. Ecmwf re-analysis project report series, ECMWF.

Gill, A.E., 1980: Some simple solutions for heatinduced tropical circulation. Quart. J. Roy. Meteor. Soc., 106, 447-462.

Held, I.M., S.W. Lyons and S. Nigam, 1989: Transients and the extratropical response to El Niño. J. Atmos. Sci., 46, 163-174.

Kiladis, G. and S.K. Sinha, 1991: ENSO monsoon 
and drought in India. in Glantz, M.H., R.W. Katz and N. Nicholls eds., Teleconnections linking worldwide climate anomalies, Cambridge University Press, 431-458.

Kobayashi, C., K. Takano, S. Kusunoki, M. Sugi and A. Kitoh, 2000: Seasonal prediction skill over the Eastern Asia using the JMA global model. Quart. J. Roy. Meteor. Soc., 126, 2111-2123.

Koster, R.D. and M.J. Suarez, 1989: A Comparative analysis of two land surface heterogeneity representation. J. Climate, 5, 1380-1390.

and - 1995: Relative contributions of land and ocean processes to precipitation variability. J. Geophys. Res., 100, 13775-13790. and - 2001: Soil moisture memory in Climate models. J. Hydrometeor., 2, 558-570.

- - and M. Heiser, 2000: Variance and Predictability of Precipitation at Seasonal to Interannual Timescales. J. Hydrometeor., 1, 26-46.

Kumar, A. and M.P. Hoerling, 1995: Prospects and limitations of seasonal atmospheric GCM predictions. Bull. Amer. Meteor. Soc., 76, 335-345.

Kuo, H.L., 1974: Further studies of the influence of cumulus convection on large scale flow. $J$. Atmos. Sci., 31, 1232-1240.

Kusunoki, S., M. Sugi, A. Kitoh, C. Kobayashi and K. Takano, 2001: Atmospheric seasonal predictability experiments by the JMA GCM. J. Meteor. Soc. Japan, 79, 1183-1206.

Lau, N.-G. and M.J. Nath, 2000: Impact of ENSO on the Variability of the Asian-Australia Monsoon as Simulated in GCM Experiments. J. Climate, 13, 4287-4309.

Liu, Y. and R. Avissar, 1999: A Study of Persistence in the Land-Atmosphere System Using a General Circulation Model and Observations. J. Climate, 8, 2139-2153.

Lorenz, E.N., 1982: Atmospheric predictability experiments with a large numerical model. Tellus, 34, 505-513.

Masuda, K., Y. Hashimoto, H. Matsuyama and T. Oki, 2001: Seasonal cycle of water storage in major river basins of the world. Geophys. Res. Lett., 28, 3215-3218.

Matsuno, T., 1966: Quasi-geostrophic motions in the equatorial area. J. Meteor. Soc. Japan, 44, 2543.

Mellor, G.L. and T. Yamada, 1974: A hierarchy of turblence-closure models for planetary boundary layers. J. Atmos. Sci., 31, 1791-1806.

Nakaegawa, T. and M. Sugi, 2001: Impact of soil moisture movement schemes in a SVATS on global climate of AGCM. Soil-VegetationAtmosphere Transfer Schemes and Large-Scale Hydrological Models, 270, 47-52.
Nobre, P.J. and J. Shukla, 1996: Variations of Sea Surface Temperature, Wind Stress, and Rainfall over the Tropical Atlantic and South America. J. Climate, 9, 2464-2479.

Ogallo, L.J., J.E. Janowiak and M.S. Halpert, 1988: Teleconnection between seasonal rainfall over East Africa and global sea-surface temperature anomalies. J. Meteor. Soc. Japan, 66, 807-821.

Oki, T. and K. Musiake, 1995: Global Atmospheric Water Balance and Runoff from Large River Basin. in Kalma, J.D. and M. Sivapalan eds., Scale Issues in Hydrological Modelling, Wiley \& Sons, Inc., 411-434.

—, T. Nisimura and P. Dirmeyer, 1999: Assesment of Annual Runoff from Land Surface Model using Total Runoff Integration Pathways (TRIP). J. Meteor. Soc. Japan, 77, 235255.

Palmer, T.N. and D.L.T. Anderson, 1994: The prospects for seasonal forecasting-A review paper. Quart. J. Roy. Meteor. Soc., 120, 755-793.

Piechota, T.C., F.H.S. Chiew, J.A. Dracup and T.A. McMahon, 1998: Seasonal streamflow forecasting in Eastern Australia and the El NiñoSouthern Oscillation. Wat. Resour. Res., 34, 3035-3044.

Randall, D. and D.M. Pan, 1993: Implementation of the Arakawa-Shubert cumulus parameterization of cumulus convectin in numerical models. J. Atmos. Sci., 46, 137-144.

Rayner, N.A., E.B. Horton, D.E. Parker, C.K. Folland and R.B. Hackett, 1996: Version 2.2 of the Global Sea-Ice and Sea Surface Temperature data set, 1931-1994. Climate research technical note, Hadley Center, Meteorological Office.

Rodell, M. and J.S. Famiglietti, 1999: Detectability of variations in continental water storage from satellite observations of the time dependent gravity field. Wat. Resour. Res., 35, 2705-2723.

Rowell, D.P., 1998: Assesing potential seasonal predictability with an ensemble of multidecadal GCM simulations. J. Climate, 11, 109-120.

Hong, S.-Y. and E. Kalnay, 2002: The 1998 Oklahoma? Texas Drought: Mechanistic Experiments with NCEP Global and Regional Models. J. Climate, 15, 945-963.

Sato, N., P.J. Sellers, D.A. Randall, E.K. Schneider, J. Shukla, J.L.K. III, Y.-T. Hou and E. Albertazzi, 1989: Effects of Implementing the simple biosphere model ( $\mathrm{SiB}$ ) in a general circulation model. J. Atmos. Sci., 46, 2757-2782.

Sellers, P.J., Y. Mintz, Y.C. Sud and A. Dalcher, 1986: Simple Biosphere model ( $\mathrm{SiB})$ for use within general circulation model. J. Atmos. Sci., 43, 505-531.

Sharma, A., 2000: Seasonal to interannual rainfall 
probabilistic forecasts for improved water supply management: Part 3-A nonparametric probabilistic forecast model. J. Hydrol., 239, 249-258.

Shibata, K. and T. Aoki, 1989: An infrared radiative scheme for the numerical models of weather and climate. J. Geophys. Res., 94, 1492314943.

and A. Uchiyama, 1992: Accuracy of the delta-four-stream approximation in inhomogeneous scattering atmosphere. J. Meteor. Soc. Japan, 70, 1097-1109.

, H. Yoshimura, M. Ohizumi, M. Hosaka and M. Sugi, 1999: A simulation of troposphere, stratosphere and mesosphere with an MRI/ JMA98 GCM. Pap. Meteor. Geophys., 50, 1553.

Shinoda, M. and R. Kawamura, 1996: Relationship between rainfall over semi-arid southern Africa, geopotential heights, and sea surface temperature. J. Atmos. Sci., 74, 21-36.

Shukla, J., 1998: A predictability in the midst of chaos: A scientific basis for climate forecasting. Science, 282, 728-731.

Sperber, K.R. and T.N. Palmer, 1996: Interannual tropical rainfall variability in general circulation model simulations asscociated with the Atmospheric Model Inercomparison Project. $J$. Climate, 9, 2727-2750.

Stern, W. and K. Miyakoda, 1995: Feasibility of seasonal forecasts inferred from multiple GCM simulations. J. Climate, 8, 1071-1085.

Sugi, M., R. Kawamura and N. Sato, 1997: A study of SST-forced variability and potential predictability of seasonal mean fields using the JMA global model. J. Meteor. Soc. Japan, 75, 717736.

Trenberth, K.E. and C.J. Guillemot, 1995: Evaluation of the Global Atmospheric Moisture Budget as seen from Analyses. J. Climate, 8, 22552272.

Trenberth, K.E., G.W. Branstator, D. Karoly, A. Kumar, N.-C. Lau and C. Ropelewski, 1998: Progress during TOGA in understanding and modeling global teleconnections associated with tropical sea surface temperatures. J. Geophys. Res., 103(C7), 14291-14324.

Uvo, C.B. and Graham, 1998: Seasonal runoff forecast for northern South America: A statistical Model. Wat. Resour. Res., 34, 3515-3524.

Vinnikov, K.Y. and A. Robock, 1996: Scales of temporal and spatial variability of midlatitude soil moisture. J. Geophys. Res., 101(D3), 71637174.

Vorosmarty, C.J., P. Green, J. Salisbury and R.B. Lammers, 2000: Global water resources: Vulnerability from Climate Change and Population Growth. Science, 289, 284-288.

Walsh, J.E., W.H. Jasperson and B. Ross, 1985: Influence of snow cover and soil moisture on monthly air temperature. Mon. Wea. Rev., 113, $756-768$.

Ward, M.N. and C.K. Folland, 1991: Prediction of seasonal rainfall in the north Nordeste of Brazil using eigenvectors of sea surface temperature. Int. J. Clmatol., 11, 711-743.

Yamaguchi, Y. and M. Shinoda, 2002: Soil moisture modeling based on multiyear observation in the Sahel. J. Appl. Meteor., 41, 1140-1146. 